\title{
The Economic Ramifications Of Multinational Corporations: Foreign Direct Investments (FDI's) And The Connection Between Technological Transfer And Productivity Growth Within Host Economies
}

\author{
Joshua Ball, (JCB0429@westminstercollege.edu), Westminster College \\ Aric Krause, Westminster College \\ Christopher S.P. Tong, Westminster College
}

\begin{abstract}
This study conducts an investigation into the impact of technology transfer as a derivative of FDI on productive efficiency within developing Asian economies through the implementation of applied empirical analysis.
\end{abstract}

\section{INTRODUCTION}

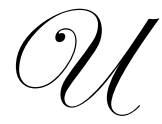

nderstanding the role that FDI and technology transfer plays is a crucial component in more fully comprehending the globally linked nature of the world's economy. Although much work has already been done on examining the impact of FDI on various aspects of economic development in developing economies, see for example as John Cantwell (1999, 2003), Campos and Kinoshinta (2002), Sahoo and Mathiyazhagan (2003), and Akinlo (2004); little attention has as of yet been paid towards investigating one particular aspect of economic development: the impact of FDI on the living standard in such developing economies. Our study aims to fill this gap by investigating the issue empirically utilizing data collected on nine developing Asian economies, namely; China, Hong Kong, India, Malaysia, Philippines, Singapore, South Korea, Taiwan, and Thailand.

This study adopts the stochastic frontier production model, which incorporates inefficiency effects into its findings. A perfunctory glance at the correlation between FDI and GDP overtime for nearly any developing economy will reveal that the two economic indicators tend to trend together; our study endeavors to look beyond simple correlative statistics and delve into the complexities of technology transfer; concerning itself primarily with evaluating how technology transfer through foreign direct investment affects productivity and evaluating how in turn increased productivity and efficiency affects the living standard in these developing economies. The findings of this study seem to indicate that by controlling certain variables such as infrastructure level, educational level, and exchange rate; technology transfer and the degree of overall openness of an economy it strongly impacts an economy's productive efficiency and consequently the living standard of the country.

\section{FOREIGN DIRECT INVESTMENT AND LIVING STANDARD}

Technology transfer through FDI can be used as a mechanism for growth and development as it results in the transfer of marketable skills to the workforce, implying a more robust potential stream of future income as 
described in McClelland (1993). This transfer of skills to the workforce can be considered as an increase in, or augmentation of, human capital. In Sen's analysis $(1989,1993)$, the stock of human capital represents the summation of beings and doings -- the ability to "be" and "do." These determine the well-being of the individual and thus comprise the individual's capabilities and functionings. Capabilities pertain to what a person can "be", and functionings refer to what a person can choose to "do", or how free a person is to choose. Capabilities include the ability of a person to engage in a well-balanced, informed life and can be considered to be self-enhancing as one who leads an informed life is able to increase the possibility of future capabilities attainment. The result of capabilities enhancement is an increase in the individual's stock of human capital and therefore in one's ability to enjoy life. When the individual is better skilled, the ability to have well-being in personal arenas is enhanced as uncertainty about surroundings is reduced.

Specifically, technology transfer through FDI results in two types of knowledge available to the local human capital stock. First, a Smithian division of labor occurs whereby skills are augmented to produce goods. Second, FDI results in the transfer of technology concerning methods of creating outputs from inputs, and for coordinating upstream and downstream aspects of the production process in terms of market finding, input choices, and access to resources, according to Casson (1997). As this knowledge is passed to the local work force, capabilities are enhanced as is the ability to generate new resource coordination and utilization knowledge. This technology transfer results in human capital accumulation which is transferable between individuals and industries. Transferability leads to the likelihood that both local entrepreneurial activities and the knowledge self-generation process can occur, as in Olson (1995). Over time, firms requiring higher order skills will have more incentive to locate locally and foster the continuation of the human capital development process. According to Schultz (1982):

While any capability produced by human investment becomes a part of the human agent and hence cannot be sold, it is nevertheless "in touch with the marketplace" by affecting wages and salaries that the human agent can earn - - a yield on the investment (pg. 104). (Quotes in original)

Human capital is considered to demonstrate positive externalities: as a person increases her capabilities, it is possible and probable that others will benefit as well, according to Ghura and Hadjimichael (1996). Lucas (1988) demonstrates that investment in human capital not only enhances the productivity of the individual but also society at large. Employees in a firm learn from older employees; children learn from their parents, managers in one firm may learn from those at other firms, implying an economy wide externality. For this reason, Lucas discusses human capital accumulation resulting from foreign direct investment as the source of both long-run technological growth and economic development and, ultimately, better standard of living.

It is important to note that where international firms choose to locate is a function not only of the set of locally determined risk factors, but also of the set of local conditions that the firm can harness to augment its set of productivity determining competitive advantages, such as infrastructure, resource conditions, and/or political or social advantages. The technology transferring firm must be able to exploit its ownership of coordination advantages wherever it chooses to locate such that enhancement of living standards through FDI can, in general, occur where local infrastructure is suitable. Broadly outlined by Munnell (1990), this observation prepares us for presentation of the methodology of this study.

\section{METHODOLOGY AND DATA COLLECTION}

A number of empirical studies, see for example Pitt and Lee (1981) and Kalirajan (1981), have estimated stochastic frontiers and predicted firm-level efficiencies using the estimated functions, and then regressed the predicted efficiencies upon firm-specific variables in an attempt to identify some of the reasons for differences in predicted efficiencies between firms in an industry. Although this two-stage estimation procedure has long been recognized as a useful exercise, it has also been long recognized as inconsistent in its assumptions regarding the independence of the inefficiency effects in the two estimation stages. To avoid this inconsistency in estimating the stochastic production frontiers of China's TVEs and finding explanations for the differences in the predicted efficiencies, this study, in following the procedures of Battese and Coelli (1995), models the stochastic frontier production function for panel data as: 


$$
Y_{i t}=\exp \left(x_{i t} \beta+V_{i t}-U_{i t}\right)
$$

where $Y_{i t}$ denotes the gross domestic product at the $t$-th observation $(t=1,2, \ldots, T)$ for the $i$-th country $(i=1,2, \ldots$, $N) ; x_{i t}$ is $(1 \times k)$ vector of values of inputs of production associated with the $i$-th country at the $t$-th observation; $\beta$ is a $(k \times 1)$ vector of unknown parameters to be estimated; the $V_{i t} s$ are assumed to be iid $N\left(0, \sigma_{v}^{2}\right)$ random errors, independently distributed of the $U_{i t} s$; the $U_{i t} s$ are non-negative random variables, associated with technical inefficiency of production, which are assumed to be independently distributed, such that $U_{i t}$ is obtained by truncation at zero of the normal distribution with mean, $Z_{i t} \delta$, and variance, $\sigma^{2} ; Z_{i t}$ is a $(1 \times m)$ vector of explanatory variables associated with technical inefficiency of production of enterprises over time; and $\delta$ is an ( $m \times 1)$ vector of unknown coefficients.

Equation (1) specifies the stochastic frontier production function in terms of the original production values. The technical inefficiency effects, i.e., the $U_{i t} s$, are assumed to be a function of a set of explanatory variables, the $Z_{i t} s$, and an unknown vector of coefficients, $\delta$. If all elements of the $\delta$-vector are equal to zero, then technical inefficiency effects are not related to the Z-variables and so the half-normal distribution stochastic frontier production model originally specified in Aigner et al. (1977) is obtained. In addition, the $U_{i t}$ in Equation (1), i.e., the technical inefficiency of the $i$-th enterprises at time $t$, can be specified as:

$U_{i t}=Z_{i t}+W_{i t}$

where the random variable, $W_{i t}$, is defined by the truncation of the normal distribution with zero mean and variance, $\sigma^{2}$, such that the point of truncation is $-Z_{i t} \delta$. Under this assumption, if a particular economy is efficient in production, then the value of its $W$ is equal to $-Z_{i t} \delta$ and hence the value of its $U$ is zero. Further, the technical efficiency of production for the $i$-th economy at time $t$ is defined as:

$T E_{i t}=\exp \left(-U_{i t}\right)=\exp \left(-Z_{i t} \delta-W_{i t}\right)$.

Therefore, if a particular economy is efficient in production, then its technical inefficiency $(U)$ is zero and its technical efficiency $(T E)$ is one, i.e., $e^{-0}=1$.

The maximum likelihood estimation method (ML) will be used to estimate Equation (1) and (2) simultaneously. With respect to the functional form of Equation (1), the Cobb-Douglas production function, for the reason of simplicity, will be applied. The likelihood function and its partial derivatives with respect to the parameters of the model are presented in Battese and Coelli (1993). In addition, to simplify the search for a suitable starting value for the iterative maximization process, $\sigma_{V}^{2}$ and $\sigma^{2}$ will, respectively, be replaced by $\sigma_{S}^{2} \equiv \sigma_{v}^{2}+\sigma^{2}$ and $\gamma=\sigma^{2} /\left(\sigma_{v}^{2}+\sigma_{s}^{2}\right)$ as suggested in Battse and Corra (1977). Under this new parameterization, the value of $\gamma$ will always lie between zero and one, and that will facilitate the hypothesis testing on whether or not the inefficiency effects are stochastic.

Here, in estimating the stochastic frontier, the nine economies under study are assumed to use two resources/inputs; i.e., capital $\left(x_{1}\right)$ and labor $\left(x_{2}\right)$ to produce one output, i.e., gross domestic product (y). Our capital input $\left(x_{1}\right)$ is a measure of accumulated depreciated investment. It is defined as the stock of accumulated capital investment in the designated country adjusted for depreciation. Since data statistics on accumulated depreciated investment is not readily available it was necessary to construct this variable from scratch for each country. To construct this variable we utilized methods similar to those in $\mathrm{Wu}$ (1999). Estimated capital stock according to the conventional formula is:

$\mathrm{K}(\mathrm{t})=\Delta \mathrm{K}(\mathrm{t})+(1-\delta) \mathrm{K}(\mathrm{t}-1)$ 
Where $\mathrm{K}(\mathrm{t})$ is the capital stock at time $\mathrm{t}, \delta$ is a given rate of depreciation, and $\Delta \mathrm{K}(\mathrm{t})$ is the incremental capital gain at time t. For our purposes in this study, data series for $\Delta \mathrm{K}(\mathrm{t})$ were back-cast to the year 1900 , so the equation was expanded to:

$\mathrm{K}(\mathrm{t})=\Sigma_{0}^{\mathrm{t}-1901}(1-\delta)^{\mathrm{k}} \Delta \mathrm{K}(\mathrm{t})+(1-\delta)^{\mathrm{t}-2003} \mathrm{~K}(1900)$

In our study we assumed 7 percent as our standard rate of depreciation and data on capital investment was taken from PENN World's database concerning percentages of real gross domestic product spent on capital investment that were converted back into actual monetary values for real gross domestic product (All figures are expressed in 1996 constant prices).

Our labor input $\left(x_{2}\right)$, represents workers in the countries in question. Information for this variable was also not readily maintained and available so the variable was constructed through manipulation of PENN World Data and there data concerning real gross domestic product per capita and population statistics yielding a measure for real gross domestic product and then consequent similar manipulation of the PENN World Data concerning real gross domestic product per worker yielding a measure for workers in the countries under investigation.

Our output, real gross domestic product (y), was taken from PENN World's database and calculated as was previously indicated through manipulation of the data concerning real gross domestic product per capita and recorded population statistics.

In this study, the technical inefficiency effects are assumed to be a function of five explanatory variables, namely the amount of inflowing foreign direct investment stock in the economy $\left(Z_{1}\right)$, the economic freedom index of the economy $\left(Z_{2}\right)$, the infrastructure index of the economy $\left(Z_{3}\right)$, the educational expenditures index of the economy $\left(Z_{4}\right)$, and the domestic interest rate of the economy $\left(Z_{5}\right)$. Although the focus of this study is to explore the impact of technology transfer, measured by using the amount of inflowing foreign direct investment, on the productive efficiency of the host economies and hence the living standards of the people resided in there, it is imperative to control for other variables that might have direct or indirect effects on productivity of these economies.

To further clarify the nature of the explanatory $\mathrm{Z}$ variables a brief explanation on how the variables were constructed follows. The variable $Z_{l}$, FDI Stock, is the recorded amount of new FDI stock accumulated as a percentage of GDP in a designated country as reported at the annual United Nations Conference on Trade and Development. The variable $Z_{2}$, the Economic Index of Freedom, is a yearly index constructed and provided for 156 countries by the Heritage Foundation in conjunction with the Wall Street Journal. The index is comprised of ten components rated on a scale from 1 to 5 . The economic index of freedom helps meaningfully gauge how appealing and welcoming a given country is to foreign economic interaction, investment, and trade. The variable $Z_{3}$, the Infrastructural Index, is an index that owing to lack of prefabricated data was constructed on our own. The index was constructed to provide a meaningful metric for comparison among relative quantities of infrastructure within the countries under investigation. The index is comprised of four infrastructural areas of interest: total road network length, paved road network length, fixed phone line (connections per 100 persons), merchant fleet dwt (dead weight tons). Data was collected on each of the four areas for all of the countries implicated in our study. The yearly data for each component of the index for each country was then compared among countries to yield a meaningful index. ${ }^{1}$ The variable $Z_{4}$, the Expenditure on Education Index, is a record of expenditure on public education as recorded by the World Bank concerning the countries under investigation as a percentage of GDP. This variable is utilized to reflect the importance of education in a given society. The variable $Z_{5}$, Interest Rate, tracks the lending interest rate in the designated countries as reported by the International Financial Statistics database.

The amount of inflowing foreign direct investment stock is modeled here to capture the effect of technology transfer on productive efficiency. It is believed that the greater the level of technology being transferred to the host economy, production should be less inefficient in that economy. Therefore, the expected sign of $\delta_{l}$, i.e., the parameter for the variable $Z_{l}$, is negative. The variable, $Z_{2}$, includes information on ten economic issues such as government

\footnotetext{
${ }^{1}$ Refer to the appendix for details on how this variable is constructed.
} 
intervention, property right, regulations, fiscal burden, and black markets. ${ }^{2}$ The larger the value of this index implies the economy in question has favorable conditions in those economic issues addressed by the index, which in turn is an indication of a more open and free economy. It is believed that the degree of openness and freedom of an economy is positively related to productive efficiency; therefore, the expected sign of $\delta_{2}$ is negative. Infrastructure, which includes both transportation facilities and communication network, always play a crucial role in production and its efficiency. Better connected road system lower transportation cost for both material inputs and final products; better communication networks make the flow of information more quickly and timely, and both of these factors will enhance productive efficiency directly. In addition, infrastructure will also affect productivity indirectly through the inflow of foreign direct investments. That is, the better the infrastructure of an economy, the greater the amount of foreign direct investment that it is likely to attract, and hence production technology can be improved with better management-know-how and more capital. As such, the expected sign of $\delta_{3}$ is also negative. Similar to infrastructure, the amount of government spending on education will also affect domestic productivity both directly and indirectly. Better human capital, through increased years of education, increases the marginal productivity of capital. Also, an economy with adequate skilled and educated labors is always a plus to multinational firms when they make decisions on where abroad to invest. Therefore, the expected sign of $\delta_{4}$ is negative, i.e., the larger the educational expenditures index, the smaller the expected productive inefficiency. The higher the interest rate, the greater is the cost of capital. Since productivity is heavily depended on the availability of capital, it is reasonable to assume a positive relationship between interest rate and productive inefficiency. The expected sign of $\delta_{4}$ is positive.

With all variables defined, the stochastic frontier production function to be estimated can formally be written as:

$\ln \left(Y_{i t}\right)=\beta_{0}+\beta_{1} \ln (\text { Capital })_{i t}+\beta_{2} \ln (\text { Labor })_{i t}+V_{i t}-U_{i t}$

where the technical inefficiency effects are defined by

$U_{i t}=\delta_{0}+\delta_{1}(\text { Foreign Direct Investment Stock })_{i t}+\delta_{2}(\text { Economic Freedom Index })_{i t}+\delta_{3}(\text { Infrastructure Index })_{i t}+$

$$
\delta_{4}(\text { Educational Expenditures Index })_{i t}+\delta_{5}(\text { Interest Rate })_{i t}+W_{i t}
$$

where $\ln$ denotes the natural logarithms. In the process of estimating the technical efficiency of the economies under study, the null hypotheses which specifies inefficiency effects are absent from the models, i.e., $\mathrm{H}_{0}: \gamma=\delta_{1}=\cdots=\delta_{3}=0$, and which specifies the inefficiency effects are not a linear function of the three chosen explanatory variables, i.e., $\mathrm{H}_{0}: \delta_{1}$ $=\delta_{2}=\delta_{3}=0$, will also be tested. This study uses data collected from Penn World Table Version 6.1, UNCAD FDI database, Statistics Finland's databases, WDI database, International Financial Statistics IFS database, the United Nations' World Investment Reports, and Heritage Foundation's Index of Economic Freedom 1995-2004.

\section{EMPIRICAL RESULTS}

\section{Regressions Results}

Table 1 shows the estimation results obtained from two different estimations. The results in columns 1 and 2 were obtained by the traditional average response function and the stochastic frontier production function. Focusing only on the results in column 1, the estimated input elasticities, i.e., $\beta_{I}$ and $\beta_{2}$, reported there are statistically significant and positive, which is consistent with the microeconomic theory. In addition, the sum of the estimated elasticities in column 1 comes, to 0.946 , which implies that the aggregate production function of the economies under study comes close to exhibit constant returns-to-scale.

Given the fact that Eq. (5) estimates production inefficiency, the estimated coefficient, $\delta_{l}$, indicates that in an economy where there is a larger accumulated amount of foreign direct investment, its production also tends to be less

\footnotetext{
${ }^{2}$ This index is constructed jointly by the Wall Street Journal and the Heritage Foundation. Details of this index can be found in the Appendix.
} 
inefficient. This result is of course consistent with the argument given earlier. The inflow of foreign direct investment brings along technology transfer and management-know-how, and they are the key components for any host economies of foreign direct investments to gain efficiency in its production. The estimated coefficient for the variable $Z_{2}$ is -0.183 , which is statistically significant at the 5 percent level and is also having the expected sign. Besides, the estimated value of $\delta_{2}$ is also the largest among the five parameters under estimation, which is an indication of the importance of an economy's degree of freedom and openness in affecting its own productivity. This result suggests that the smaller the degree of government intervention, the clearer the property right is defined, and the less severe is the condition of black markets in an economy, the less inefficient is its production. The estimated coefficient for the variable $Z_{3}$ is -0.0335 , which is statistically significant at the 1 percent level. As expected, the better the infrastructure of an economy, the less inefficient is its production. For the variable $Z_{4}$, its estimated coefficient is -0.05 , which is also statistically significant at the 1 percent level. This result shows that in this technology era, investment in human capital continues to be a crucial factor in enhancing productive efficiency. The estimated coefficient for the variable $Z_{5}$ is 0.011 , which is statistically significant at the 5 percent level. Interest rate, being the cost of capital, will slash productivity if it is at too high a level as suggested by the result here. In conclusion, it seems that all the explanatory variables included in Eq. (5) are correctly chosen because they all carry the expected sign and are statistically significant at least at the 5 percent level.

\section{Hypothesis Testing}

Note also that in column 2 of Table 1, the log-likelihood function for the full stochastic frontier model is calculated to be 58.661 and the value for the OLS fit of the production function as shown in column one is 22.912 , which is smaller than that for the full frontier model. This implies that the generalized likelihood-ratio for testing the absence of the technical inefficiency effects from the frontier, i.e., $\gamma=\delta_{0}=\delta_{1}=\delta_{2}=\delta_{3}=\delta_{4}=\delta_{5}=0$, is calculated to be LR = $2[22.912-58.661]=71.498$.

This value is statistically significant because it exceeds 13.401 , which is the critical value obtained from Table 1 of Kodde and Palm (1986) for the degrees of freedom equal to $7 .^{3}$ Hence the null hypothesis of no technical inefficiency effects in the aggregate production of the economies under study is rejected as reported in Table 2.

Note also that the ML estimate for $\gamma$ is 0.99999 with estimated standard error of 0.000015 . These results are consistent with the conclusion that the true $\gamma$-value is concluded to be greater than zero (in the test above). However, we also see that the $\gamma$-estimate is not significant different from zero, which indicates that the stochastic frontier model may not be significant different from the deterministic frontier, in which there are no random errors in the production function. On the other hand, the fact that the $\gamma$-estimate is significantly different from zero, we can conclude that the traditional response function is not an adequate representation for the aggregate production of the economies under study, given the specification of the stochastic frontier and inefficiency model, defined by Eqs. (4) and (5).

The second hypothesis considered in Table 2 specifies that the inefficiency effects are not a linear function of the chosen explanatory variables, i.e., $\gamma_{1}=\gamma_{2}=\gamma_{3}=\gamma_{4}=\gamma_{5}=0$. The value of the log likelihood function of this restricted model is 37.30; therefore, the generalized likelihood-ratio for testing these five restrictions is calculated to be:

$\mathrm{LR}=-2[37.30-58.661]=42.722$.

\section{Estimated Efficiencies}

Table 3 reports the estimated productive efficiencies of the nine Asian economies over time; the same information is also depicted in Figure 1. Note that the results reported here are the estimated relative efficiencies, not absolute. The last row of the table reports the average productive efficiencies of the economies over time. The results here indicate that, on average, India, Taiwan, and China are the relatively more productive economies for the period under study. The production of India in particular has been approaching the production frontier during the last few years of the study, and its estimated productive efficiency is 1 in year 2002, i.e., totally efficient. The last column of Table 4, labeled as CSA, provides the cross-sectional averages for each of the 18 years under study, which is also shown in Figure

\footnotetext{
${ }^{3}$ In this case, the likelihood ratio statistic will have asymptotic distribution equal to a mixture of chi-square distribution.
} 
2. It is clear from Figure 2 that the average productive efficiency of the nine Asian economies under study had increased from the beginning of the period until year 1997, and then it dropped to about 0.554 in the following year before it bounced back to the previous level in year 2000.

These results are all consistent with the economic realities of the whole Asian region for the period under study. The rapid economic development of the Asian economies during the early 90's had many economists all over the world believed that they are the future of the global economy. The incredible economic achievements happened in this part of the world were even called by many as the Asian miracle until the bubble burst in 1997 when the Asian financial crisis raid the area. This is the reason why the average productivity trend shown in Figure 2 keeps on increasing until it gets to year 1997 and then drops. The rebounding of the productivity trend since year 2000 reflects the recovery of most of the economies from the recession caused by the crisis. The better performance of India and China as suggested by our

Table 1 Estimates for Parameters

\begin{tabular}{lcc}
\hline & $\begin{array}{c}\text { Traditional Average } \\
\text { Response Function }\end{array}$ & $\begin{array}{c}\text { Stochastic Frontier } \\
\text { Production Function }\end{array}$ \\
Constant $\left(\beta_{0}\right)$ & 3.412 & 4.306 \\
& $(0.483)$ & $(0.607)$ \\
In Capital $\left(\beta_{1}\right)$ & 0.662 & 0.694 \\
ln Labor $\left(\beta_{2}\right)$ & $(0.030)$ & $(0.04)$ \\
& 0.284 & 0.190 \\
Inefficiency Model & $(0.016)$ & $(0.026)$ \\
Constant $\left(\delta_{0}\right)$ & & \\
Foreign Direct Investment Stock $\left(\delta_{1}\right)$ & & 1.235 \\
Economic Freedom Index $\left(\delta_{2}\right)$ & & $(0.127)$ \\
& & 0.00059 \\
Infrastructure Index $\left(\delta_{3}\right)$ & & $(0.00032)$ \\
Educational Expenditures Index $\left(\delta_{4}\right)$ & & -0.183 \\
Interest Rate $\left(\delta_{5}\right)$ & & $(-0.036)$ \\
& & -0.033 \\
Variance Parameters & & $(-0.011)$ \\
Sigma-squared $\left(\sigma_{\mathrm{S}}^{2}\right)$ & -0.050 \\
Gamma $(\gamma)$ & $(-0.020)$ \\
Log-likelihood function & & 0.011 \\
\hline
\end{tabular}


Table 2

Tests of Hypotheses for the Coefficients of the Explanatory Variables for the Technical Inefficiency Effects in the Stochastic Frontier Production Functions

\begin{tabular}{|c|c|c|c|c|}
\hline \multirow[t]{2}{*}{ Null Hypothesis } & \multirow[t]{2}{*}{ Log (likelihood) } & \multirow[t]{2}{*}{$\chi_{0.95}^{2}$} & \multirow[t]{2}{*}{$\chi_{0.90}^{2}$} & Test \\
\hline & & & & Statistic \\
\hline $\mathrm{H} 0: \gamma=\delta 0=\delta 1=\ldots=\delta 5=0$ & 22.912 & 11.911 & 9.998 & 71.498 \\
\hline $\mathrm{H} 0: \delta 1=\delta 2=\delta 3=\delta 4=\delta 5=0$ & 37.30 & 11.070 & 9.236 & 42.722 \\
\hline
\end{tabular}

This test statistic is also statistically significant because it exceeds 15.0863 , which is the critical value obtained from the $\chi^{2}$ distribution table with the level of significance equals to 1 percent. As such, the null hypothesis is rejected and the test result indicates that the joint effect of the five chosen variables on the inefficiencies of the aggregate production of the nine Asian economies under study is significant.

estimation results can be explained by the facts that: (1) both of these economies are not victims of the Asian financial crisis, and (2) they are the economies that have been attracting a lot of foreign direct investments in recent years due to their market potentials and cheap labor. Although the Chinese economy did slow down a little bit in 1997 and 1998, it was more due to the fact that China insisted on not devaluating her currency while some neighboring economies suffering from recession, such as Philippines, Thailand, Korea, and Taiwan, had devaluated their currencies. The Asian financial crisis is definitely a non-issue in the case of India simply due to the fact that India does not have a financial market. In conclusion, our estimates do match up with the economic realties of the time.

Table 3

Estimated Productive efficiencies

\begin{tabular}{cccccccccccc}
\hline Time & China & Hongkong & India & Korea & Malaysia & Philippines & Singapore & Taiwan & Thailand & CSA \\
& & & & & & & & & & & \\
1985 & 0.6517 & 0.4833 & 0.7444 & 0.4792 & 0.4653 & 0.4436 & 0.3016 & 0.6295 & 0.3668 & 0.5073 \\
1986 & 0.6489 & 0.5113 & 0.762 & 0.4996 & 0.4334 & 0.4502 & 0.2946 & 0.672 & 0.3637 & 0.5151 \\
1987 & 0.6418 & 0.5463 & 0.7687 & 0.52 & 0.4354 & 0.4786 & 0.3102 & 0.7164 & 0.383 & 0.5334 \\
1988 & 0.6298 & 0.561 & 0.8009 & 0.5377 & 0.4681 & 0.5078 & 0.3329 & 0.7272 & 0.4122 & 0.5531 \\
1989 & 0.5752 & 0.5508 & 0.8111 & 0.5344 & 0.4948 & 0.5265 & 0.349 & 0.7397 & 0.4289 & 0.5567 \\
1990 & 0.5791 & 0.55 & 0.8064 & 0.5401 & 0.5181 & 0.5319 & 0.3619 & 0.7353 & 0.4442 & 0.563 \\
1991 & 0.6155 & 0.564 & 0.7776 & 0.5421 & 0.5504 & 0.5124 & 0.3607 & 0.7426 & 0.4388 & 0.5671 \\
1992 & 0.6607 & 0.5809 & 0.7869 & 0.527 & 0.5405 & 0.5088 & 0.3597 & 0.7448 & 0.4323 & 0.5713 \\
1993 & 0.6966 & 0.597 & 0.8084 & 0.5184 & 0.5424 & 0.5129 & 0.3821 & 0.7418 & 0.4321 & 0.5813 \\
1994 & 0.6895 & 0.6077 & 0.8345 & 0.5256 & 0.5525 & 0.5157 & 0.3809 & 0.7423 & 0.4361 & 0.5872 \\
1995 & 0.6841 & 0.5889 & 0.8511 & 0.5324 & 0.5564 & 0.5338 & 0.3949 & 0.7402 & 0.4439 & 0.5917 \\
1996 & 0.6806 & 0.5783 & 0.8881 & 0.5309 & 0.5433 & 0.5488 & 0.4223 & 0.7414 & 0.4375 & 0.5968 \\
1997 & 0.6632 & 0.5747 & 0.9183 & 0.5195 & 0.5338 & 0.5502 & 0.4278 & 0.7438 & 0.3998 & 0.5923 \\
1998 & 0.66 & 0.5177 & 0.9306 & 0.4451 & 0.4429 & 0.5365 & 0.4027 & 0.7333 & 0.3301 & 0.5554 \\
1999 & 0.6814 & 0.5612 & 0.9511 & 0.4831 & 0.5302 & 0.5741 & 0.4152 & 0.7608 & 0.4163 & 0.597 \\
2000 & 0.6852 & 0.5646 & 0.9698 & 0.4797 & 0.5348 & 0.5811 & 0.4205 & 0.7648 & 0.4166 & 0.6019 \\
2001 & 0.6884 & 0.568 & 0.9862 & 0.4768 & 0.5395 & 0.5879 & 0.4257 & 0.7678 & 0.4163 & 0.6063 \\
2002 & 0.6912 & 0.5714 & 0.9999 & 0.4743 & 0.5442 & 0.5946 & 0.4308 & 0.7699 & 0.4153 & 0.6102 \\
Average & 0.6568 & 0.5598 & 0.8553 & 0.5092 & 0.5126 & 0.5275 & 0.3763 & 0.7341 & 0.4119 & 0.571506 \\
\hline
\end{tabular}




\section{Efficiencies and Living Standards}

The hypothesis of our study is that technology transfer, measured by foreign direct investment, impacts productive efficiency positively, which in turn affects the living standards of the people in the host economies. The first part of our hypothesis is verified by the results of the stochastic frontier analysis in general and the estimated coefficient of the $Z_{I}$ variable in particular. To complete our study, now we need to verify the second part of our hypothesis by linking the estimated productive efficiencies with the living standards of the economies under study. It is a well known basic economic concept that although real GDP is a good measure of economic growth and development, it is not a good indicator of living standards. Here, we will adopt per capita real GDP as a proxy of the living standards. Table 4 shows the simple correlation coefficients between the estimated productive efficiencies and per capita real GDP for the economies under study. The results in the table indicate that there is a strong correlation between the two variables in general. In addition, the t-statistics of the correlation coefficients of seven out of nine economies are statistically significant. Therefore, it is our conclusion that technology transfer does directly and positively affect productive efficiency and indirectly affect the living standards of the people.

Figure 1

Estimated Productive Efficiencies over Time

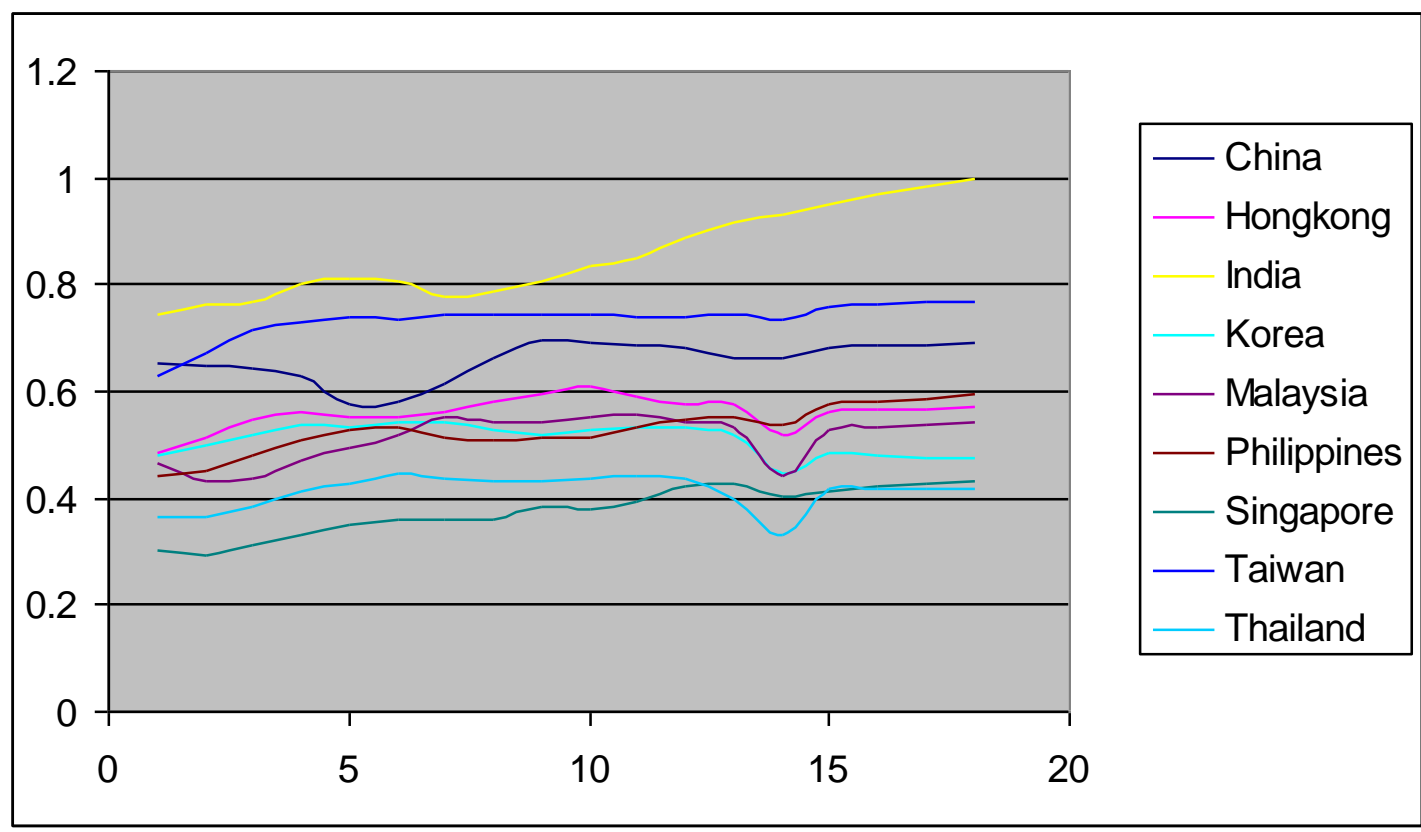

Figure 2

Average Estimated Efficiencies over Time

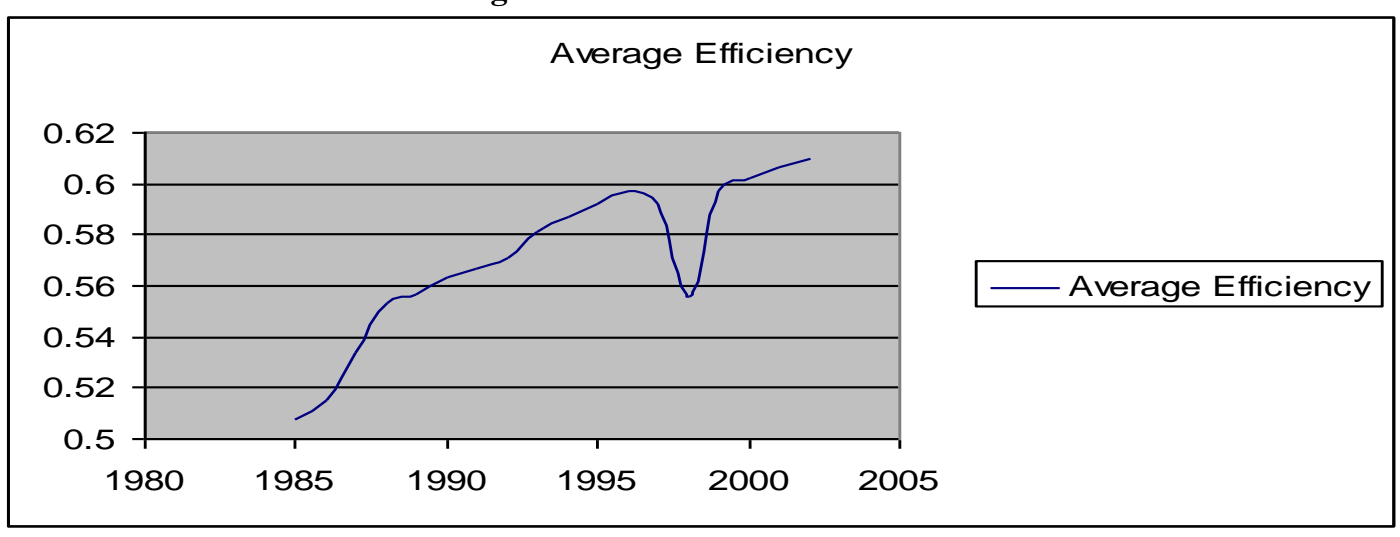




\section{CONCLUSION}

The world we live in today is very different from the world of yesteryears; focus in aspects of understanding has shifted towards grasping the proverbial larger picture and emphasis has changed focal point from the part to the whole. This is particularly evident concerning economic growth. Potential for growth has shifted away from being primarily a self-absorbed internal affair towards something vehemently concerned with the interdependence and interaction among economies. In perceiving that we live in an increasingly globally linked economy it is evident that understanding interaction between economies is paramount. FDI is one area of economic interaction that has continued to be a strong area of interest. Efforts to understand FDI and its economic impact on developing economies have led to a large number of inquisitive empirical studies. One aspect of understanding the role FDI plays that to date has seen markedly less-substantial inquiry involves how technology transfer through FDI affects productivity in developing economies. Our study has been a concentrated effort towards evaluating this relationship and an analogous inquiry into the effect of productivity fluctuations on living standards in these developing economies and possible factors that play a role in attracting FDI and the technology transfer that comes along with it in the form of decreased inefficiency, heightened productivity and impacted living standard.

From our study, the empirical evidence concludes that technology transfer, in general, does positively impact productive efficiency, which in turn also empirically supports a direct correlation with living standards. What's more, our results also indicate that among the nine Asian economies within our study India and China are the two economies that have achieved relatively higher productive efficiency. These estimation results supported in our study are consistent with the economic realities of the region within the period under study. The huge market potentials of these two economies have been attracting an abundant amount of technology transfer through foreign direct investment, which of course is one of the main reasons for their relatively superior performance in production. The results of our study also suggest that education, infrastructure, economic freedom, and interest rate are all playing a substantial role in affecting the productivity of an economy. Given the fact that being productive is the source of being competitive, and competitiveness has long been revered to be a main factor for economic growth, in accordance with our study, it would seem that governments should carefully reevaluate public investments in education and infrastructure, create and maintain a reasonable degree of economic freedom, and wisely implement fiscal and monetary policies in order to continue to attract FDI, play a bigger role in the global economy, and ultimately improve relative living standards within there developing economies.

Table 4

Estimated Correlation Coefficients

\begin{tabular}{lcl}
\hline Country & Correlation Coefficient $(\mathbf{r})$ & t-statistic \\
China: & 0.723 & $4.185^{*}$ \\
Hong Kong: & 0.753 & $4.576^{*}$ \\
India: & 0.994 & $35.516^{*}$ \\
Korea: & 0.245 & 1.012 \\
Malaysia: & 0.734 & $4.326^{*}$ \\
Philippines: & 0.941 & $11.074^{*}$ \\
Singapore: & 0.937 & $10.770^{*}$ \\
Taiwan: & 0.772 & $4.865^{*}$ \\
Thailand: & 0.309 & 1.297 \\
\hline
\end{tabular}

* Significance at the 1 percent level. 


\section{References}

1. Aigner, D. J., Lovell, C.A.K., \& Schmidt, P. (1977). "Formulation and estimation of stochastic frontier production function models", Journal of Econometrics, 86, 21-37.

2. Battese, G.E., \& Coelli, T.J. (1993). "A stochastic frontier production function incorporating a model for technical inefficiency effects". Working papers in Econometrics and Applied Statistics No 69, Department of Econometrics, University of New England.

3. Battese, G.E., \& Coelli, T.J. (1995). "A model for technical inefficiency effects in a stochastic frontier production function for panel data", Empirical Economics, 20, 325-332.

4. Battese, G.E., \& Corra, G.S. (1977). "Estimation of a production frontier model: with application to the pastoral zone of eastern Australia", Australian Journal of Agricultural Economics, 21, 169-179.

5. Campos, N., \& Kinoshita, Y. (2002). "Foreign Direct Investment as Technology Transferred: Some Panel Evidence from the Transition Economies", Manchester School, 70, iss. 3, 398-419.

6. Cantwell, J. (Ed.,) (1999). "Foreign Direct Investment and Technological Change". Volume I: Theories of Technological Change. Edward Elgar Publishing Limited, Massachusetts.

7. Cantwell, J. (Ed.), (1999). "Foreign Direct Investment and Technological Change". Volume II: Technology Creation and its Economic Impact. Edward Elgar Publishing Limited, Massachusetts.

8. Cantwell, J. \& Iammario, S. (2003). "MNC Technological Activities and Economic Wealth. An Analysis of Spatial Distribution in the European Union". In Cantwell, J. and S. Iammario, (Eds.), Multinational Corporations and European Regional Systems of Innovation. Routledge: UK.

9. Casson, M. (1997). Information and Organization: A New Perspective on the Theory of the Firm. Oxford University Press, New York.

10. Ghura, D. and Hadjimichael, M. (1996). "Growth in Sub-Saharan Africa", International Monetary Fund Staff Papers 43: 605-635.

11. Kalirajan, K. (1981). “An econometric analysis of yield variability in paddy production”, Canadian Journal of Agricultural Economics, 29: 283-294.

12. Kodde, D.A., \& Palm, F.C. (1986). "Wald criteria for jointly testing equality and inequality restrictions", Econometrica, 54: 1243-1248.

13. Lucas, R. (1988). "On the Mechanics of Economic Development”, Journal of Monetary Economics, 22: 342.

14. McClelland, P. (1993). The American Search for Economic Justice. Basil Blackwell, Massachusetts.

15. Munnell, A. (1990). "How Does Public Infrastructure Affect Regional Economic Performance?", New England Economic Review, 52: 11-32.

16. Olson, M. (1995). "The New Institutional Economics and Third World Development". In Harriss, J. et al., (Eds). The New Institutional Economics and Third World Development. Routledge: New York.

17. Pitt, M.M., \& Lee, M-F. (1981). "The measurement and sources of technical inefficiency in the Indonesian weaving industry", Journal of Development Economics, 9, 43-64.

18. Sahoo, D., \& Mathiyazagan, M., (2003). "Economic Growth in India: Does Foreign Direct Investment Inflow Matter?", Singapore Economic Review, 48: iss. 2, 151-71.

19. Schultz, T. (1993). The Economics of Being Poor. Blackwell: Massachusetts.

20. Sen, A. (1993). "Capability and Well Being". In Nussbaum, M. and Sen, A. (Eds). The Quality of Life. Clarendon: UK.

21. Sen, A. (1989). "Development as Capability Expansion", Journal of Development Planning 17: 41-58.

22. Wu, Yanrui. (1999). "Regional integration, productivity and growth: evidence from the economies of Taiwan, Hong Kong, Guangdong, and Fujian”, Paper presented at Hong Kong Baptist University. 
$\underline{\text { Notes }}$ 